\title{
Front Matter: Volume 6617
}

, "Front Matter: Volume 6617," Proc. SPIE 6617, Modeling Aspects in Optical Metrology, 661701 (18 June 2007); doi: 10.1117/12.746778

SPIE. Event: Optical Metrology, 2007, Munich, Germany 


\title{
PROCEEDINGS OF SPIE
}

\section{Modeling Aspects in Optical Metrology}

\author{
Harald Bosse \\ Bernd Bodermann \\ Richard M. Silver \\ Editors
}

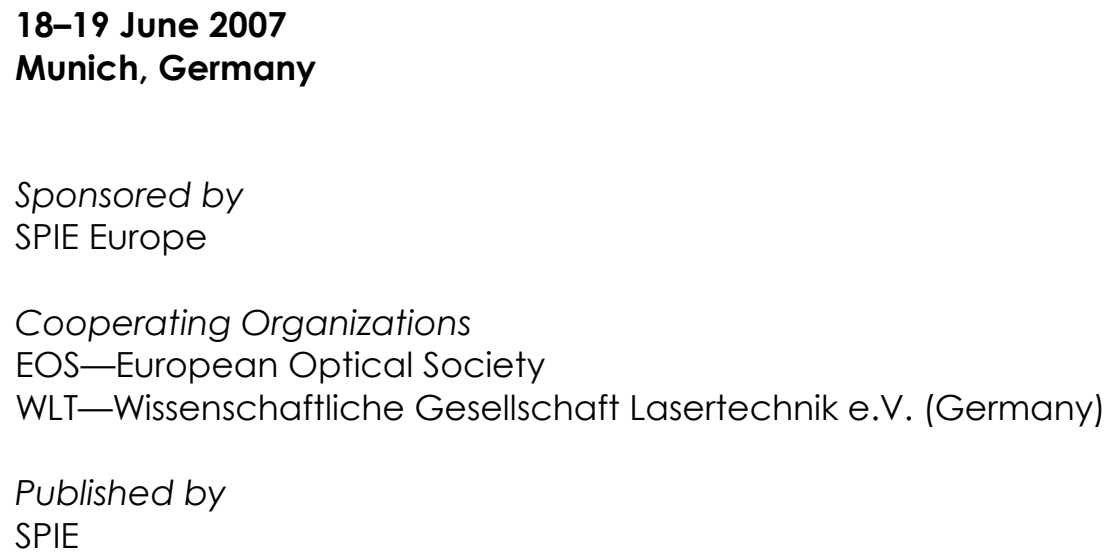


The papers included in this volume were part of the technical conference cited on the cover and title page. Papers were selected and subject to review by the editors and conference program committee. Some conference presentations may not be available for publication. The papers published in these proceedings reflect the work and thoughts of the authors and are published herein as submitted. The publisher is not responsible for the validity of the information or for any outcomes resulting from reliance thereon.

Please use the following format to cite material from this book:

Author(s), "Title of Paper," in Modeling Aspects in Optical Metrology, edited by Harald Bosse, Bernd Bodermann, Richard M. Silver, Proceedings of SPIE Vol. 6617 (SPIE, Bellingham, WA, 2007) Article CID Number.

ISSN 0277-786X

ISBN 9780819467591

Published by

SPIE-The International Society for Optical Engineering

P.O. Box 10, Bellingham, Washington 98227-0010 USA

Telephone 1 360/676-3290 (Pacific Time) · Fax 1 360/647-1445

http://www.spie.org

Copyright @ 2007, The Society of Photo-Optical Instrumentation Engineers

Copying of material in this book for internal or personal use, or for the internal or personal use of specific clients, beyond the fair use provisions granted by the U.S. Copyright Law is authorized by SPIE subject to payment of copying fees. The Transactional Reporting Service base fee for this volume is $\$ 18.00$ per article (or portion thereof), which should be paid directly to the Copyright Clearance Center (CCC), 222 Rosewood Drive, Danvers, MA 01923. Payment may also be made electronically through CCC Online at http://www.copyright.com. Other copying for republication, resale, advertising or promotion, or any form of systematic or multiple reproduction of any material in this book is prohibited except with permission in writing from the publisher. The CCC fee code is 0277$786 \times / 07 / \$ 18.00$.

Printed in the United States of America.

Publication of record for individual papers is online in the SPIE Digital Library.

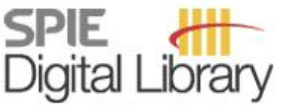

SPIEDigitalLibrary.org

Pagination: Proceedings of SPIE follow an e-First publication model, with papers published first online and then in print and on CD-ROM. Papers are published as they are submitted and meet publication criteria. A unique, consistent, permanent citation identifier (CID) number is assigned to each article at the time of the first publication. Utilization of CIDs allows articles to be fully citable as soon they are published online, and connects the same identifier to all online, print, and electronic versions of the publication. SPIE uses a six-digit CID article numbering system in which:

- The first four digits correspond to the SPIE volume number.

- The last two digits indicate publication order within the volume using a Base 36 numbering system employing both numerals and letters. These two-number sets start with 00, 01, 02, 03, 04 , $05,06,07,08,09,0 A, 0 B \ldots$. 0Z, followed by 10-1Z, 20-2Z, etc.

The CID number appears on each page of the manuscript. The complete citation is used on the first page, and an abbreviated version on subsequent pages. 


\section{Contents}

ix Conference Committee

xi Introduction

SESSION 1 OPTICAL SYSTEMS

661703 Simulation of the detectors response of an autocollimator [6617-02]

G. Fütterer, Physikalisch-Technische-Bundesanstalt (Germany)

661704 Capabilities and limitations of paraxial operator approach for modeling of nano-scale feature evaluation [6617-03]

A. Normatov, B. Spektor, J. Shamir, Israeli Institute of Technology (Israel)

661705 Modeling image formation on pixelated devices for vision systems using wave-front coding [6617-04]

S. Bosch, F. Gómez-Morales, G. Carles, Univ. de Barcelona (Spain); J. Ferré-Borrull, Univ. Rovira i Virgili (Spain)

661706 Lateral shear and digital holographic microscopy to check dynamic behaviour of biological cell [6617-05]

L. Miccio, Istituto Nazionale di Ottica Applicata del CNR (Italy) and LENS (Italy); S. Grilli, Istituto Nazionale di Ottica Applicata del CNR (Italy); S. De Nicola, A. Finizio, Istituto di Cibernetica E. Caianiello del CNR (Italy); P. Ferraro, Istituto Nazionale di Ottica Applicata del CNR (Italy)

661707 MTF assessment of dual waveband diffractive lenses [6617-35]

J. M. Infante Herrero, M. C. de la Fuente, Indra Sistemas S.A. (Spain)

661708 The influence of target distance to lens distortion variation [6617-36]

C. Bräuer-Burchardt, Fraunhofer IOF Jena (Germany)

661709 Numerical simulation tool for synthetic speckle pattern images and their intensity-based integration under variable conditions for metrology applications [6617-37]

F. Riechert, Univ. of Karlsruhe (Germany); G. Bastian, Univ. of Applied Sciences Trier

(Germany); U. Lemmer, Univ. of Karlsruhe (Germany)

66170A Modeling of image formation of a low-cost white-light bench microscope with a linear CMOS image sensor: its application in metrology [6617-38]

M. P. Macedo, ISEC, Instituto Superior de Engenharia de Coimbra (Portugal) and Univ. de Coimbra (Portugal); A. J. Barata, A. G. Fernandes, C. M. Correia, Univ. de Coimbra (Portugal)

66170B Modeling of propagation of ultrashort light pulses in optical systems [6617-39]

A. Miks, J. Novak, P. Novak, Czech Technical Univ. (Czech Republic) 
66170C Multiple multipole program analysis of metallic optical waveguides (Invited Paper) [6617-06]

C. Hafner, X. Cui, A. Bertolace, R. Vahldieck, ETH Zurich (Switzerland)

66170D Sharp trench waveguide bend with photonic crystals: simulation, fabrication, and characterisation [6617-07]

X. Cui, C. Hafner, F. Robin, ETH Zurich (Switzerland); D. Erni, Univ. of Duisburg-Essen

(Germany); K. Tavzarashvili, R. Vahldieck, ETH Zurich (Switzerland)

66170E Frequency-domain simulations of optical antenna structures [6617-08]

C. Hafner, X. Cui, A. Bertolace, R. Vahldieck, ETH Zurich (Switzerland)

66170F Apodised fibre Bragg grating design for gain flattening of EDFA [6617-40]

A. Khare, UIT RGPV Bhopal (India); A. Khare, BHEL Bhopal (India)

$66170 \mathrm{G}$ Scattering at silver-enhanced gold particles inside subwavelength-apertured metallic layers [6617-41]

T. Glaser, Institute for Physical High Technology (Germany)

$66170 \mathrm{H}$ Computer and experimental modeling of light scattering at random and fractal surfaces [6617-48]

O. V. Angelsky, A. P. Maksimyak, P. P. Maksimyak, Chernivtsi National Univ. (Ukraine)

661701 Effect of broadband illumination on reconstruction error of phase retrieval in optical metrology [6617-09]

G. R. Brady, J. R. Fienup, Univ. of Rochester (USA)

66170J Phase retrieval using a random amplitude mask for wavefront sensing [6617-10]

A. Anand, Institut für Technische Optik (Germany) and Institute for Plasma Research (India);

G. Pedrini, W. Osten, Institut für Technische Optik (Germany); P. Almoro, Univ. of the Philippines (Philippines)

66170K The optical vortex interferometer with a wavefront division [6617-11]

J. Masajada, A. Popiołek-Masajada, M. Leniec, Wrocław Univ. of Technology (Poland)

66170L Applications of optical vortex birefringence compensator [6617-42]

M. Borwińska, P. Kurzynowski, A. Popiołek-Masajada, Wrocław Univ. of Technology (Poland)

66170M Opportunities and limits for interferometry in production control [6617-46]

T. Blümel, R. Neubert, R. Kafka, FISBA OPTIK GmbH (Germany); W. Boeck, C. Zellweger,

FISBA OPTIK AG (Switzerland) 
$66170 \mathrm{~N}$ Practical implementation of the complex wavefront modulation model for optical alignment [6617-12]

H. Lee, Univ. of Oxford (United Kingdom) and Yonsei Univ. (South Korea); G. B. Dalton, Univ. of Oxford (United Kingdom) and Rutherford Appleton Lab. (United Kingdom); I. A. J. Tosh, Rutherford Appleton Lab. (United Kingdom); S.-W. Kim, Yonsei Univ. (South Korea)

661700 Robust Shack-Hartmann wavefront sensing with ultraflat microaxicons [6617-13] R. Grunwald, M. Bock, Max-Born Institute for Nonlinear Optics and Ultrafast Spectroscopy (Germany); S. Huferath, Bremen Institute of Applied Beam Technology (Germany)

66170Q Fresnel wavefront propagation model for shearography shape measurement [6617-15] A. Anand, ITO Institut für Technische Optik (Germany) and Institute for Plasma Research (India); R. M. Groves, X. Schwab, G. Pedrini, W. Osten, ITO Institut für Technische Optik (Germany)

$66170 \mathrm{R}$ Single fringe pattern demodulation using local adaptable quadrature filters [6617-16] J. C. Estrada, M. Servin, Ctr. de Investigaciones en Óptica, A.P. (Mexico)

\section{SESSION5 MAXWELL SOLVERS}

66170 Adaptive MBPE algorithm for speeding up the computation [6617-17]

K. Tavzarashvili, Ch. Hafner, ETH Zentrum (Switzerland); D. Karkashadze, Tbilisi State Univ. (Georgia); X. Cui, R. Vahldieck, ETH Zentrum (Switzerland)

$66170 \mathrm{U}$ Enhancements to FDTD modeling for optical metrology applications [6617-19] B. Salski, Warsaw Univ. of Technology (Poland); M. Celuch, QWED (Poland); W. Gwarek, Warsaw Univ. of Technology (Poland)

$66170 \mathrm{~V} 3 \mathrm{D}$ simulations of electromagnetic fields in nanostructures using the time-harmonic finite-element method [6617-20]

S. Burger, L. Zschiedrich, F. Schmidt, Zuse Institute Berlin (Germany) and JCMwave GmbH (Germany); R. Köhle, Qimonda AG (Germany); T. Henkel, B. Küchler, C. Nölscher, Qimonda Dresden $\mathrm{GmbH} \&$ Co (Germany)

\section{SESSION 6 MODELING IN SEMICONDUCTOR METROLOGY}

$66170 \mathrm{~W}$ Model-based analysis of the limits of optical metrology with experimental comparisons (Invited Paper) [6617-21]

R. M. Silver, R. Attota, E. Marx, National Institute of Standards and Technology (USA)

$66170 \mathrm{X}$ In-chip overlay metrology for $45 \mathrm{~nm}$ processes [6617-22]

Y. S. KU, H. L. Pang, Industrial Technology Research Institute (Taiwan); N. P. Smith, Nanometrics Incorporated (Taiwan); L. Binns, Nanometrics Incorporated (United Kingdom)

$66170 Y$ An approach to validation of rigorous modeling in optical CD microscopy by comparison of measurement results with independent methods [6617-47]

B. Bodermann, H. Bosse, Physikalisch-Technische Bundesanstalt (Germany) 
661710 Comparison of rigorous modelling of different structure profiles on photomasks for quantitative linewidth measurements by means of UV-or DUV-optical microscopy [6617-24]

G. Ehret, B. Bodermann, M. Woehler, Physikalisch-Technische Bundesanstalt (Germany)

661712 Optical characterization procedure for large thin films [6617-49]

J. F. Trigo, J. Herrero, CIEMAT (Spain); L. Soriano, Univ. Autónoma de Madrid (Spain);

M. T. Gutiérrez, CIEMAT (Spain)

\section{SESSION 7 SCATTEROMETRY}

661713 In-line etching process control using dynamic scatterometry (Invited Paper) [6617-26] S. Soulan, M. Besacier, LTM-CNRS (France); T. Leveder, CEA-LETI (France); P. Schiavone, LTM-CNRS (France)

661714 Optical scatterometry with analytic approaches applied to periodic nano-arrays including anisotropic layers [6617-27]

I. Abdulhalim, Ben Gurion Univ. of the Negev (Israel)

661715 Scatterometry from crossed grating structures in different configurations [6617-28] T. Schuster, S. Rafler, W. Osten, Institut für Technische Optik (Germany); P. Reinig, T. Hingst, Qimonda Dresden (Germany)

661716 Numerical analysis of DUV scatterometry on EUV masks [6617-29]

M. Wurm, B. Bodermann, Physikalisch-Technische Bundesanstalt (Germany); R. Model, Physikalishe-Technische Bundesanstalt (Germany); H. Groß, Physikalisch-Technische Bundesanstalt (Germany)

661717 Structure modeling for scatterometric characterization of photoinduced surface-relief gratings [6617-30]

P. C. Logofatu, I. Apostol, National Institute for Lasers, Plasma and Radiation Physics (Romania); M.-C. Castex, Univ. Paris-Nord (France); V. Damian, I. lordache, M. Bojan, D. Apostol, National Institute for Laser, Plasma and Radiation Physics (Romania)

\section{SESSION 8 EUV SCATTEROMETRY}

661718 Finite element analysis of EUV lithography [6617-31]

J. Pomplun, S. Burger, F. Schmidt, Zuse Institute Berlin (Germany) and JCMwave GmbH (Germany); F. Scholze, C. Laubis, Physikalisch-Technische Bundesanstalt (Germany); U. Dersch, Advanced Mask Technology Ctr. GmbH \& Co. (Germany)

661719 A rigorous solution for electromagnetic scattering from any kind of asperities of multilayer 1-D structures in the x-ray-VUV ranges [6617-32]

L. I. Goray, Institute for Analytical Instrumentation (Russia)

$66171 \mathrm{~A}$ The influence of line edge roughness and CD uniformity on EUV scatterometry for CD characterization of EUV masks [6617-33]

F. Scholze, C. Laubis, Physikalisch-Technische Bundesanstalt (Germany); U. Dersch, Advanced Mask Technology Ctr. (Germany); J. Pomplun, S. Burger, F. Schmidt, Zuse Institute Berlin (Germany) and JCMwave GmbH (Germany) 
$66171 \mathrm{~B}$ Optimal sets of measurement data for profile reconstruction in scatterometry [6617-34] H. Gross, Physikalisch-Technische Bundesanstalt (Germany); A. Rathsfeld, Weierstrass Institute for Applied Analysis and Stochastics (Germany); F. Scholze, M. Bär, PhysikalischTechnische Bundesanstalt (Germany); U. Dersch, Advanced Mask Technology Ctr. (Germany)

Author Index 
Downloaded From: https://www.spiedigitallibrary.org/conference-proceedings-of-spie on 26 Apr 2023

Terms of Use: https://www.spiedigitallibrary.org/terms-of-use 


\title{
Conference Committee
}

\author{
Symposium Chairs
}

Wolfgang Osten, Universität Stuttgart (Germany)

Malgorzata Kujawinska, Warsaw University of Technology (Poland)

Ralph P. Tatam, Cranfield University (United Kingdom)

Conference Chair

Harald Bosse, Physikalisch-Technische Bundesanstalt (Germany)

Conference Cochairs

Bernd Bodermann, Physikalisch-Technische Bundesanstalt (Germany)

Richard M. Silver, National Institute of Standards and Technology (USA)

Program Committee

Markus Bär, Physikalisch-Technische Bundesanstalt (Germany)

Jörg Bischoff, TEL/Timbre Technologies, Inc. (USA) (USA)

Sven Burger, Zuse Institute Berlin (Germany) and JCMwave GmbH (Germany)

Andreas Erdmann, Fraunhofer Institut IISB (Germany)

Christian Hafner, ETH Zürich (Switzerland)

Wolfgang Holzapfel, Dr. Johannes Heidenhain GmbH (Germany)

Bernd H. Kleemann, Carl Zeiss AG (Germany)

Roderick Köhle, Qimonda AG (Germany)

Giovanni Mana, INRIM, Torino (Italy)

Wolfgang Osten, Institut für Technische Optik (Germany)

Andreas Rathsfeld, Weierstrass Institute for Applied Analysis and Stochastics, (Germany)

Thomas Scherübl, Carl Zeiss SMS GmbH, (Germany)

Patrick Schiavone, LTM, CNRS (France)

Michael Totzeck, Carl Zeiss SMT AG (Germany)

Jari P. Turunen, University JoensuU (Finland)

Frank Wyrowski, Friedrich-Schiller-University Jena (Germany) and LightTrans GmbH (Germany)

Session Chairs

$1 \quad$ Optical Systems

Harald Bosse, Physikalisch-Technische Bundesanstalt (Germany) 
2 Optical Wave Propagation

Bernd H. Kleemann, Carl Zeiss AG (Germany)

3 Interferometry and Phase Retrieval I

Frank Wyrowski, Friedrich-Schiller-University Jena (Germany) and LightTrans $\mathrm{GmbH}$ (Germany)

$4 \quad$ Interferometry and Phase Retrieval II

Bernd Bodermann, Physikalisch-Technische Bundesanstalt (Germany)

5 Maxwell Solvers

Christian Hafner, ETH Zürich (Switzerland)

6 Modeling in Semiconductor Metrology

Andreas Erdmann, Fraunhofer Institut IISB (Germany)

$7 \quad$ Scatterometry

Marcus Bär, Physikalisch-Technische Bundesanstalt (Germany)

8 EUV Scatterometry

Richard M. Silver, National Institute of Standards and Technology (USA) 


\section{Introduction}

The proposal to arrange a new conference within the framework of the SPIE Optical Metrology Symposium dedicated especially to "Modeling Aspects in Optical Metrology" was initially suggested by Prof. Wolfgang Osten, chairman of the conference on "Optical Measurement Systems for Industrial Inspection." The idea behind it was to establish a forum to present and discuss in particular basic methods, techniques, and algorithms which are necessary for a proper modeling and simulation of applied optical metrology techniques.

The use of optical metrology in production control is increasing and thus it is of ever greater importance to be able to fully understand the optical measurement process, which requires the ability of quantitatively predicting the dependence of the output of an optical sensor or measurement system on certain variations of the measurement object, the sensor itself, or the measurement environment. Only if these influences on the measurement result are well understood and appropriately taken into account in a suitable model of the measurement process, the measurement result and its associated measurement uncertainty can be used for example for reliable control of production processes. Moreover, the ability to understand and model a measurement process is also a prerequisite for comparison of the results with other independent measurement methods in so-called cross-calibration analyses.

A group of optical measurement techniques which is strongly dependent on appropriate modeling techniques and which has recently been further developed are scatterometry methods used for advanced process control in microelectronics production. Here forward calculations of the resulting diffraction patterns from different periodic grating structures have been refined with respect to computational accuracy as well as speed and approaches have been reported to address the inverse scattering problem, too. Scatterometry topics thus are one focal point of the new conference.

The two-day conference covers the following sessions: optical systems, optical wave propagation, interferometry and phase retrieval, Maxwell solvers, modeling in semiconductor metrology, scatterometry, and EUV scatterometry. I would like to thank all contributors as well as the cochairs and the members of the program committee for their support of this new conference, and I am looking forward to seeing you in Munich!

Harald Bosse 
Downloaded From: https://www.spiedigitallibrary.org/conference-proceedings-of-spie on 26 Apr 2023

Terms of Use: https://www.spiedigitallibrary.org/terms-of-use 